\title{
PROSPECÇÃo DE CENÁRIOS PARA CADEIA PRODUTIVA DO FEIJÃo GOIANO
}

\author{
Paulo Eterno Venâncio ASSUNÇÃO*
}

\author{
*Faculdade de Filosofia e Ciência Humanas de Goiatuba - FAFICH. paulo_eterno05@ hotmail.com \\ Recebido em: 19/05/2014 - Aprovado em: 30/06/2014 - Disponibilizado em: 30/07/2014
}

\begin{abstract}
Resumo: feijão é um produto presente na dieta básica dos brasileiros, constituindo uma das suas principais fontes de proteína de origem vegetal, estando presente na pauta de alimento de vários países além do Brasil. Utilizando-se de uma pesquisa exploratória em relação à cadeira de produção do feijão, o estado da arte atual da cultura e o desenvolvimento tecnológico que ela apresenta, o objetivo do trabalho foi discutir e colocar as incertezas apresentadas pela cultura, propondo a discussão de cenários prospectivos para a demanda de feijão. Foram desenvolvidos três cenários com perspectivas diferentes para a cultura. Assim como a análise do ambiente interno e externo da cultura através da matriz de análise SWOT. Pela análise, o feijão é pouco competitivo em relação às culturas concorrentes, mas apresenta um ambiente propício para o seu crescimento e aumento da competitividade. Há a necessidade de ações mais firmes por parte do governo para que os agricultores encontrem mais estabilidade e segurança durante o processo produtivo.
\end{abstract}

Palavras-chave: Prospecção de cenários. Análise SWOT. Competitividade. Feijão.

\section{SCENARIOS PROSPECTIVE OF BEAN TRADE CHAIN}

\begin{abstract}
: bean is a product present in the basic diet of brazilian, contituing on of it's main plant-protein sources, being present in the list of foods form various countries besides Brazil. Using na exploraty research in relation of bean trade chain, the state of the art current of the corp and the technological development that the crop presents,. This paper aims was to discuss the uncertainties presented by tha crop, proposing discussion of prospective scenarios to the demand of bean. Were developed three scenarios with different perspectives to the crop. As well an analysis of the internal and external atmosphere of the crop through the matriz SWOT analysis. The resultds indicate the bean are uncompetitive against competing crops. Although there are considerable barriers, there are also favorable conditions for increasing competitiveness. There is a need of a firmer actions by the government so that farmers are more stability and security during the production process.
\end{abstract}

Key words: Scenarios prospective. SWOT analysis. Competitiveness. Bean.

\section{INTRODUÇÃO}

O feijão é um produto presente na dieta básica dos brasileiros, constituindo uma das suas principais fontes de proteína de origem vegetal. O feijão figura entre as culturas mais produzidas no Brasil e no mundo, sendo que sua importância explora o aspecto econômico, por relevância enquanto fator cultural, de segurança alimentar e nutricional (BARBOSA; GONZAGA, 2012).

A média de consumo nacional de feijão está na ordem de 12,7 kg brasileiro/ano
(EMBRAPA, 2012). A preferência do consumidor está ligada a região de consumo, diferindo principalmente quanto à cor, tipo e o tamanho do grão de feijão. O feijão é cultivado ao longo do ano, na maioria dos estados brasileiros, proporcionando uma oferta estável de feijão no mercado interno. Mas nem todo o feijão produzido internamente é suficiente para suprir a demanda interna, sendo, por isso, necessária a 
importação de feijão (ASSUNÇÃO; WANDER, 2012).

O cenário nacional tem-se apresentado favorável em relação à quantidade de feijão que tem sido produzida.

O feijão apresenta uma taxa de crescimento da produção em torno de $0,9 \%$ e de consumo em torno de $1,1 \%$ ao ano, para o período correspondente a 2010/2011 a 2020/2021 e, atualmente, o consumo médio anual de feijão tem sido em torno de 3,5 milhões de toneladas ao ano (BRASIL, 2011).

A cultura feijão tem crescido em relação às tecnologias que estão envolvidas com sua produção. Barbosa et al. (2010), Quintela (2001), Paula Júnior et al. (2008) destacam que os avanços tecnológicos obtidos pela pesquisa, disponibilizam ao setor produtivo do feijão tecnologias como: cultivas mais produtivas e adaptadas às diferentes regiões brasileiras, manejos mais adequados do solo, adubação e calagem da maneira e nas doses certas, manejo integrado de pragas e doenças, dentre outros avanços observados para o fortalecimento da cadeia produtiva do feijão.

Com a importância apresentada pela cultura, objetivou-se com este trabalho analisar a competitividade da cadeia de produção do feijão, prospectando possíveis cenários de desenvolvimento para a cultura com base na literatura publicada sobre o tema feijão e com base em indícios de desenvolvimento da cultura, buscando também através da identificação das principais barreiras e das oportunidades existentes para cultura.

O estudo se justiça pela escassez de publicações focando o gerenciamento da cadeia produtiva do feijão e a não existência de estudos sobre a prospecção dos cenários futuros da cadeira de produção de feijão na literatura especializada.

\section{REFERENCIAL TEÓRICO}

\subsection{Competitividade}

O termo competitividade é amplamente utilizado pelos mais diversos setores de produção, mas sua definição na literatura acadêmica é confusa e deficiente, compreendendo muitas partes de um mesmo problema, que se torna difícil, poder estabelecer uma definição ao mesmo tempo abrangente e útil (FARINA, 1998).

O conceito de competitividade está ligado com os princípios da econômica liberal. Para Ferraz et al. (1996), a competitividade pode ser entendida a partir de duas vertentes de entendimento do conceito. $\mathrm{Na}$ primeira, defendem os autores, a competitividade é vista como o desempenho de uma empresa ou produto, fazendo com que as análises dos resultados sejam traduzidas em determinações da competitividade revelada. O principal indicador que se tem, segundo essa ótica, está ligado com a participação que o produto em estudo ou 
empresa tem em um determinado mercado (market share).

As empresas agroindustriais competitivas são aquelas que conseguem reconhecer a especificidade das transações com as quais ela lida, apresentando a capacidade para se desenvolver e sustentar vantagens competitivas frente aos seus concorrentes (SIFFERT FILHO; FAVERET, FILHO, 1998). Neste sentido, João e Lourenzani (2011), defendem que a competitividade das empresas agroindustriais está relacionada com fatores endógenos e exógenos as firmas, pois vantagens competitivas dependem da eficiência da cadeia de valor e também de condições relacionadas à infraestrutura, políticas governamentais, pesquisa e outros fatores.

João e Lourenzani (2011) ainda destacam que é necessária a interação entre todos os elos do sistema, a fim de buscar vantagens competitivas que proporcionem competitividade a todos que compõem a cadeia, seja no mercado nacional, seja no mercado internacional. As organizações do agronegócio ainda enfrentam algumas peculiaridades inerentes ao setor de produção ao qual estão inseridas, como a perecibilidade, sazonalidade, mudanças climáticas entre outros fatores que estão completamente fora do controle, que são barreiras naturais à competitividade (JOÃO; LOURENZANI, 2011, ARAÚJO, 2007)

Farina e Zylbersztajn (1994) e Araújo (2007) destacam que existem quatro aspectos, ou forças, que impendem, ou interferem na competitividade do agronegócio: (1) o ambiente macroeconômico; (2) as tendências sociais e demográficas; (3) o acesso a equipamentos/tecnologias; (4) as regulamentações do governo.

João e Lourenzani (2011) concluem que a competitividade das empresas, é resultado de políticas públicas e privadas, individuais e coletivas.

\subsection{Prospecção de Cenários}

Tentar entender o que acontecerá no futuro tem sido uma das perguntas mais frequentes feitas pelo ser humano. $\mathrm{Na}$ essência, sempre queremos saber o que acontecerá no amanhã longínquo ou próximo, com isso, procuramos métodos e técnicas que possam nos ajudar em tal intento e nas organizações produtivas o desejo é o mesmo, conseguir saber o que acontecerá no futuro (SOUZA; TAKAHASHI, 2012).

Há uma impossibilidade de saber ao certo o que acontecerá no futuro. Dada a essa impossibilidade, a técnica de construção de cenários vem para auxiliar nesse trabalho, ajudando descrições de situações futuras que sejam plausíveis e consistentes e que irão ajudar os gestores e líderes das organizações no planejamento das ações atuais e futuras, preparando para que haja mudanças com intenção de seguir o caminho pré-traçado (WRIGHT; SPERS, 2006). 
A literatura especializada apresenta diversas definições para o termo cenário. Wright e Spers (2006) e Schwartz (2000) afirmam que a elaboração de cenários não é um exercício de predição, mas perfaz um exercício de construir descrições plausíveis e consistentes de situações futuras que podem acontecer, apresentando uma ligação entre a situação vivida atualmente e cada cenários que é proposto para o futuro, fazendo o destaque dos fatores relevantes às decisões que precisam ser tomadas para que o cenários futuros sejam concretizados.

Schwartz (2000) ainda destaca que os cenários podem ser vistos como plataformas para conversações estratégicas que conduzem a aprendizagem organizacional contínua a respeito de decisões-chave e prioritárias para a organização em questão. Para Porter et al. (1991), os cenários são recortes feitos sobre alguns aspectos do futuro, o seu enfoque deve ser aquele que possua a maior relevância para o prognóstico desejado.

Godet (1993) destaca que a construção de cenários é como uma descrição futura detalhada de uma situação, que deve considerar as ações dos principais atores e a probabilidade estimada dos eventos que podem ser considerados incertos, os quais devem ser articulados para que haja a realização da passagem do estado atual para o estado futuro previsto.

Schoemaker (1995) define a técnica de construção de cenários como processo estruturado de imaginar futuros possíveis de acontecimento. Raele (2010) defende que para haja a estruturação dos cenários é preciso seguir dois elementos fundamentais, utilizados por vários outros autores: a análise das tendências e das incertezas ambientais, que seriam as variáveis-chave para a construção de roteiros futuros.

Para Schnaars e Topol (1987) o terno cenário é a combinação de três características básicas: narrativas fluídas, múltiplas projeções futuras e progressão de eventos futuros. Os autores ainda destacam, que cenários são mais estruturados quando são constituídos de narrativas fluídas do que por estimativas quantitativas precisas. Silva et al. (2012) faz notar, que a abordagem por uma narração fluída oferece aos seus usuários insights sobre o processo e os mecanismos necessários para a mudança.

Fahey e Randall

complementam que cenários são narrativas de projeções alternativas, que são plausíveis, de uma parte específica do futuro, podendo oferecer descrições contrastantes como vários aspectos incertos do futuro, onde podem se desenvolver. Silva et al. (2012) destacam que essas definições propostas, podem trazer à luz a contribuição que os cenários podem oferecer.

Barbosa e Gatti Júnior (2012) enfatizam que a construção de uma visão de futuro pode variar de uma estrutura extrapolativa, que utiliza ferramentas 
quantitativas que sigam uma tendência natural à evolução; podendo, com isso, adotar ou um formato exploratório, como a consulta a especialistas, ou um modelo normativo. Os autores ainda destacam que a construção de cenários propõe uma visão pluralista do futuro.

Huss (1988) considera que o resultado mais importante, da ferramenta de cenário, não é predizer exatamente a sequência de eventos que possivelmente acontecerá, ela deve oferecer entendimento sobre a dinâmica do ambiente, tendênciaschave para monitorar e os limites dos desfechos do futuro no qual se pretende planejar. Silva et al. (2012) destaca que esses insights auxiliam os tomadores de decisão, se não prever pontos de inflexão, pelo menos conseguirem acessar quando as condições estão corretas para que haja a mudança estrutural de maior porte.

Para que haja a elaboração dos cenários, é necessário, que o cenarista considere um conjunto de forças que atuam sobre o sistema que está sendo estudado (SILVA et al., 2012). Os autores ressaltam que a consideração de tais forças não deve se limitar à extrapolação de tendências passadas, fazendo com que a análise fique presa a cenários que não foram muito propícios, temendo que eles possam ocorrer novamente. Devem ser levados em consideração cenários que não foram favoráveis, mas eles não devem nortear a análise, para não comprometer as ações que serão tomadas.
Schnaars e Topol (1987), Wright e Spers (2006) e Silva et al. (2012) destacam que é preciso ir além e adotar uma abordagem pluralista de futuro no momento da análise, sendo balizada por forças restritivas e por forças propulsoras que atuam sobre as variáveis do sistema, bem como nos limites naturais ou sociais dentro dos quais as variáveis podem evoluir no horizonte de tempo em análise.

Coates (2000) faz a sugestão que os cenários devem ser elaborados a partir da identificação e definição do universo de preocupação, definição das variáveis que serão importantes para moldar o futuro das ações, identificação dos temas para os cenários e, por fim, a criação dos cenários.

Silva et al. (2012) afirma que para uma implicação da abordagem a aprendizagem é fundamental. Fahey e Randall (1998) afirmam que a aprendizagem por cenários tem partida de quatro elementos: uso efetivo do conhecimento adquirido, desafio ao min-set dos gestores, discussão e diálogo coletivo e fornecimento contínuo de inputs para a tomada de decisão. Sobre esse aspecto, Silva et al. (2012) ainda ressaltam, que o processo de construção e desenvolvimento permite não apenas que os indivíduos envolvidos revejam suas premissas, mas também que os grupos, que ocupam diferentes funções dentro da organização, possam discutir posições e maneira de pensar, não perdendo como foco final o uso aplicado do conhecimento gerado na tomada de decisão. 
Os conceitos de prospecção e estratégias estão intimamente ligados, pois, estratégia usa a visão de futuro e inovação; prospecção usa pré-atividade e pró-atividade (GODET, 2000). Silva et al. (2012) destaca que os conceitos se encontram na medida em que a estratégia chama o procedimento prospectivo para clarificar escolhas sobre o futuro, onde permite a antecipação pelo estudo das possíveis e desejáveis mudanças, chamada pré-atividade, e a preparação da ação para provocar as mudanças desejáveis, chamada pró-atividade.

Silva et al. (2012) enfatiza, que, a exploração e a preparação para o curso de ação que será tomado são acompanhados por cinco questões:

Q0 - Quem sou eu?

Q1 - O que pode acontecer?

Q2 - O que eu posso fazer?

Q3 - O que eu efetivamente vou

fazer?

$$
\text { Q4 - Como eu vou fazer? }
$$

A construção de cenários implica na participação de uma variedade de pessoas - especialistas, estrategistas e gerentes organizados em redes, com a intenção de criar representações alternativas do futuro planejado, atuando ainda na função de criação de sentido que desafia os paradigmas estratégicos, repensando as fronteiras internas e externas da organização (ROUBELAT, 2000). Para Silva et al. (2012) todo o esforço empregado na construção de cenários parece justificar-se sempre que a organização puder elaborar respostas às suas perguntas cruciais sobre o futuro.

\subsection{Análise SWOT}

A análise SOWT, Strengths (Forças), Weaknesses (Fraquezas), Oportunities (Oportunidades) e Threats (Ameaças), foi desenvolvida pelos pesquisadores Kenneth Andrews e Roland Cristensen, professores de Havard Business School, posteriormente aplicadas por inúmeros acadêmicos em estudos, visando o entendimento da competitividade da organização. Através das quatro variáveis, é possível fazer o levantamento das forças e fraquezas da empresa, das oportunidades e ameaças do meio no qual a empresa está inserida (SILVA et al., 2011). Rodrigues et al. (2005) destaca que quando os pontos fortes de uma organização estão alinhados com os fatores críticos de sucesso para satisfazer as oportunidades de mercado, a empresa seguirá o caminho da competitividade no longo prazo.

$$
\text { A análise SWOT é uma }
$$
ferramenta utilizada na análise de ambiente e serve como base para o planejamento estratégico e de gestão de uma organização (SILVA et al., 2011). É um instrumento simples e poderoso na sua utilização, sendo amplamente utilizado pelo mundo no momento da análise de uma organização, do qual derivam estratégias pró-ativas, para aproveitar oportunidades, ou reativas, para 
minimizar as ameaças (CASTRO et al., 2005).

\section{A análise SWOT é uma} ferramenta utilizada para o delineamento das estratégias, na qual se examina o relacionamento entre os fatores internos $\mathrm{e}$ externos que influenciam o negócio (MÜLLER, 2003). A matriz de análise SWOT é um modelo conceitual para efetuar análises sistemáticas que facilitem o cruzamento entre os fatores externos (oportunidades e ameaças) e internos (forças e fraquezas), podendo ser aplicada em uma nação, região, território, indústria ou empresas (FUSCALDI; MARCELINO, 2008).

$$
\text { Martins (2006) e Daychouw }
$$

(2007) destacam que a análise SWOT é uma das práticas mais comuns nas empresas voltadas para pensamento estratégico e marketing, embora seja uma ferramenta simples, os autores ressaltam que é relativamente trabalhosa de produzir, mas a prática constante pode trazer ao profissional uma visão mais ampla e aprimorada dos negócios.

Daychouw (2007) ainda destaca, que é uma ferramenta simples para posicionar ou verificar a posição estratégica da empresa no ambiente em que ela está inserida. Silva et al. (2011) ressalva que a análise SWOT serve como ferramenta de análise de cenários (ou análises de ambiente), sendo muito utilizada como base para posicionar a gestão e o planejamento estratégico de uma organização.
Análise SWOT faz-se uma ferramenta importante para que a organização consiga analisar e entender o ambiente no qual ela está inserida. Silva et al. (2011), destaca que a empresa que consegue ter uma visão clara e objetiva sobre quais são suas forças e fraquezas no ambiente interno e suas oportunidades e ameaças no ambiente externo, seus tomadores de decisão conseguem elaborar estratégias afim de obter vantagem competitiva e melhor desempenho organizacional.

\subsubsection{Análise Externa}

A análise externa se ocupa das principais perspectivas de evolução do mercado em que a organização atua. Compreende os fatores que são provenientes do meio envolvente onde a organização está inserida, portanto, as decisões e circunstâncias que estão fora do controle direto da organização. Esta análise deve conseguir encontrar circunstâncias que possam constituir oportunidades para a organização; ou, alternadamente, proteger-se, construindo barreiras contra as ameaças externas (DYSON, 2004).

Para Chiavenato (2003), a análise interna consiste na identificação de oportunidades ou ameaças e suas respectivas causas priorizadas, localizadas no ambiente externo da empresa, negócio ou território, entendido como fatores ou situações as quais podem ser aproveitadas ou neutralizadas, que 
podem afetar positivamente ou negativamente os resultados esperados. A análise dos aspectos internos da organização permite ao gestor consciência sobre os pontos fortes e fracos que a organização apresenta (ALMEIDA, 2010).

\subsubsection{Análise Interna}

A análise interna compreende os principais aspectos que diferenciam a organização ou seus produtos dos seus concorrentes diretos no mercado. É ligada diretamente com as decisões em níveis de desempenho que a empresa pode obter. Os pontos fortes são as vantagens internas que a organização consegue ter em relação aos seus principais concorrentes. Está ligada com o que a empresa produz de maneira direta, analisando o que se pode fazer para melhorar o desempenho interno com base no que as concorrentes tem feito no mesmo sentido (DYSON, 2004).

Porter (2002) resume que a análise interna é o conjunto de recursos alocados em uma organização, sendo, recursos internos sobre os quais a organização tem controle e que deverão ser utilizados para o alcance de seus objetivos, que incluem: recursos físicos, humanos, logísticos, operacionais, financeiros e mercadológicos.

\subsubsection{Forças}

Matos et al. (2007) define forças como os recursos e habilidades de que dispõe uma organização para explorar as oportunidades e minimizar as ameaças. As forças são as variáveis internas e controláveis que propiciam condições favoráveis para a organização em relação ao seu ambiente, sendo características ou qualidades que podem influenciar positivamente o desempenho da organização (REZENDE, 2008).

Para Pereira et al. (2002), é o fato de importância dentro do ambiente competitivo que diferencia a empresa de seus concorrentes e eventuais novos entrantes, somando isso ao rápido poder de mobilização operacional, o que permite que a empresa responda rapidamente às necessidades do mercado.

As forças são fatores internos positivos que a empresa tem controle dentro de todos os seus processos, e devem ser explorados ao máximo para que a empresa mantenha-se com um bom posicionamento de mercado e consiga diminuir suas fraquezas.

\subsubsection{Fraquezas}

As fraquezas são as inibições que as organizações apresentam em sua capacidade de desempenho e devem ser superadas para evitar a diminuição do desempenho e como consequência a falência 
da organização (MATOS et al., 2007). São os aspectos mais negativos referentes à relação empresa/produto, serviço ou unidade de negócio, devem ser fatores controláveis pela própria empresa e relevantes para o planejamento estratégico (MARTINS, 2007).

Silva et al. (2011) enfatizam que a fraqueza é uma condição da empresa totalmente desfavorável, deve ser monitorada constantemente, melhoradas ou eliminada para que, futuramente, não venha dificultar a competitividade da empresa. Os autores ainda destacam, que para obter um bom desempenho a organização deve trabalhar as quatro diretrizes citadas, somente assim, a empresa conseguirá alcançar o objetivo de ser a primeira no mercado ao qual pertence.

\subsubsection{Oportunidades}

Oportunidades são situações, tendências ou fenômenos externos, atuais ou potenciais, que podem contribuir para concretização dos objetivos estratégicos (CALAEAS et al., 2006). Para Martins (2007), as oportunidades são aspectos mais positivos do produto/serviço da empresa em relação ao mercado onde ela tem sua participação ou pretende participar, sendo fatores que não podem ser controlados pela própria empresa e relevantes para o planejamento estratégico.

As oportunidades para a organização são as variáveis externas e não controláveis, que podem criar as condições favoráveis para a organização, desde que a empresa tenha condições ou interesse em utilizá-las (REZENDE, 2008). Martins (2006) ainda considera as oportunidades como chances que uma empresa tem para atender os clientes, suprindo uma ou mais necessidades ainda não satisfeitas ou mal satisfeitas pelo mercado, analisando as possibilidades e potencialidades de êxito do novo negócio. Silva et al. (2011) destacam que as oportunidades estão ligadas com a lucratividade da empresa, pois podem ampliar a sua receita.

\subsubsection{Ameaças}

Calaes et al. (2006) consideram as ameaças situações ou fenômenos externos, atuais ou potenciais, que podem prejudicar a execução de objetivos estratégicos. Para Martins (2007) as ameaças são aspectos mais negativos do produto/serviço da empresa em relação ao mercado onde ela está ou irá se inserir, são fatores que não podem ser controlados pela empresa e são relevantes para o planejamento estratégico.

Para Morais (2008), as ameaças são as forças que vem de fora da organização e que podem impactar no sucesso das operações, influenciando na competição, na capacidade operacional e o no custo de aumentos dos bens produzidos ou próprios da empresa.

Para Silva et al. (2011) as ameaças são fatores do ambiente externo que 
impactam diretamente na empresa e não podem ser controlados, eles podem prejudicar seu desenvolvimento e acarretar em perca de posicionamento e competitividade de mercado. O objetivo principal da empresa deve ser tentar diminuir a influência dessas ameaças em suas atividades.

\section{METODOLOGIA}

Este estudo tem característica de pesquisa exploratória, em o seu principal, objetivo é o aprimoramento de ideias ou a descoberta de instituições, sendo que seu planejamento é bastante flexível, de modo que possa possibilitar a consideração dos mais variados aspectos relativos ao fato estudado (GIL, 2009). A estrutura metodológica do presente trabalho foi o levantamento de dados secundários.

Para Selltiz et al. (1965) a pesquisa exploratória permite ganhar familiaridade com o fenômeno estudado e a definir questões mais específicas que poderão ser investigadas em estudos subsequentes. Segundo Gil (2009), a pesquisa bibliográfica é amplamente utilizada como técnica de investigação em pesquisas exploratórias, podendo ser desenvolvida a partir de material já elaborado, constituído principalmente de livros e artigos científicos. Gil (2009), ainda afirma, que em quase todos os estudos são exigidos algum tipo de trabalho de natureza exploratória, mas existem pesquisas desenvolvidas exclusivamente a partir de fontes bibliográficas, como o presente trabalho.

Foram consultadas referências bibliográficas relevantes sobre o agronegócio do feijão, sobre a prospecção de cenários, buscando um método que mais se adaptasse ao objetivo do presente trabalho, assim como referências bibliográficas sobre a matriz de análise SWOT.

\section{RESULTADOS E DISCUSSÃO}

\subsection{Modelo teórico e metodologia de prospecção de cenários}

Para meios de desenvolvimento do trabalho, a abordagem adotada no mesmo, considera que os cenários não têm o foco de prever o futuro, mas tem o objetivo de ser uma fonte de informações e entendimento para nortear as futuras decisões que podem ser tomadas no presente para que o objetivo visto no futuro seja alcançado.

No desenvolvimento do trabalho foi seguido os passos propostos por Wright e Spers (2006) no momento da construção de cenários:
1) Definição do escopo e objetivo dos cenários;
2) Identificação das variáveis, tendências e eventos fundamentais;

3) Estruturação das variáveis dos cenários; 
4) Projeção dos estados futuros das variáveis e sua probabilidade de ocorrência;

5) Identificação dos temas motrizes dos cenários;

6) Montagem de uma matriz morfológica para cada cenário;

7) Redação e validação dos cenários.

O desenvolvimento do trabalho contou com a utilização de dados secundários, pois a comercialização e a demanda de feijão apresenta grande volume de textos na literatura científica, essa literatura foi utilizada no presente trabalho. Assim como dados em relação às pesquisas científicas para o desenvolvimento tecnológico da cultura se encontram disponíveis na literatura. $\mathrm{O}$ foco do presente estudo foi fazer a discussão a cerca dos possíveis cenários de produção para a cultura do feijão. Foi seguido as etapas do modelo de Wright e Spers (2006), que definiram assim:

1) Escopo e objetivo dos cenários: efeitos na demanda futura de feijão decorrente do desenvolvimento $\mathrm{da}$ tecnologia, com o horizonte de tempo focado em 2020. Em relação aos stakeholders da cultura, destacam-se os governos, bancos (que concedem financiamentos para a produção da cultura), consumidores (pois regulam o aumento da produção), empresas de pesquisa $\mathrm{e}$ mercados intermediários.

2) Variáveis, tendências e eventos fundamentais: com base no levantamento da literatura, trabalhos como Ferreira (2002) e Barbosa e Gonzaga (2012), relacionou-se as seguintes variáveis como aquelas que podem impactar a demanda por feijão, na ótica da evolução tecnológica:

- Desenvolvimento de cultivares mais produtivas;

- Desenvolvimento de cultivares com maior resistência a doenças;

- Aumento do consumo de feijão;

- Aceitação por parte dos consumidores de produtos com valor agregado;

- Aumento das exportações do produto.

3) Estruturação das variáveis dos cenários: as variáveis foram estruturadas para demonstrar a 
relação de causa e efeito entre

elas.

- Cultivares mais produtivas - maior volume de produção diminuição do preço aumento do consumo demanda por feijão;

- Aceitação de produtos com valor agregado novos mercados valores maiores - maior lucratividade demanda de feijão.
4) Projeção dos estados futuros: para cada variável, foram avaliados três cenários futuros que serão a base para a análise morfológica.

Quadro1: Estado futuro das variáveis

\begin{tabular}{|c|c|c|c|}
\hline & Estado futuro 1 & Estado futuro 2 & Estado futuro 3 \\
\hline $\begin{array}{lr}\text { Desenvolvimento } & \text { de } \\
\text { cultivares } & \text { mais } \\
\text { produtivas } & \end{array}$ & $\begin{array}{l}\text { Sem } \\
\text { desenvolvimento } \\
\text { de cultivares mais } \\
\text { produtivos }\end{array}$ & $\begin{array}{l}\text { Poucos cultivares } \\
\text { novos com pouco } \\
\text { acréscimo à } \\
\text { produtividade }\end{array}$ & $\begin{array}{l}\text { Muitas cultivares } \\
\text { com produtividade } \\
\text { a cima das } \\
\text { utilizadas }\end{array}$ \\
\hline $\begin{array}{l}\text { Desenvolvimento de } \\
\text { cultivares com maior } \\
\text { resistência a doenças }\end{array}$ & $\begin{array}{l}\text { Sem } \\
\text { desenvolvimento } \\
\text { de cultivares mais } \\
\text { resistentes }\end{array}$ & $\begin{array}{l}\text { Cultivares com } \\
\text { pouca resistência a } \\
\text { doenças }\end{array}$ & $\begin{array}{l}\text { Cultivares com } \\
\text { grande resistência } \\
\text { a doenças }\end{array}$ \\
\hline $\begin{array}{l}\text { Aumento do consumo } \\
\text { de feijão }\end{array}$ & $\begin{array}{l}\text { Sem aumento do } \\
\text { consumo }\end{array}$ & $\begin{array}{l}\text { Aumento a baixo } \\
\text { do esperado no } \\
\text { consumo }\end{array}$ & $\begin{array}{l}\text { Grande aumento } \\
\text { no consumo de } \\
\text { feijão }\end{array}$ \\
\hline $\begin{array}{l}\text { Aceitação por parte dos } \\
\text { consumidores de } \\
\text { produtos com valor } \\
\text { agregado }\end{array}$ & $\begin{array}{l}\text { Não aceitação de } \\
\text { produtos com } \\
\text { valor agregado }\end{array}$ & 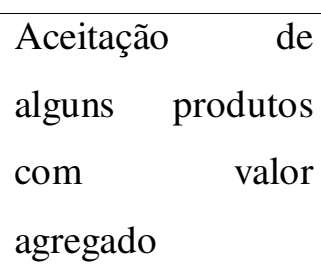 & $\begin{array}{l}\text { Completa } \\
\text { aceitação de } \\
\text { produtos com } \\
\text { valor agregado }\end{array}$ \\
\hline $\begin{array}{l}\text { Aumento das } \\
\text { exportações do produto }\end{array}$ & $\begin{array}{l}\text { Sem aumento nas } \\
\text { exportações }\end{array}$ & $\begin{array}{l}\text { Aumento a baixo } \\
\text { da média das } \\
\text { exportações }\end{array}$ & $\begin{array}{l}\text { Entrada em novos } \\
\text { mercados } \\
\text { importadores de } \\
\text { feijão }\end{array}$ \\
\hline
\end{tabular}

Fonte: elaborados pelo autor. 
mercado a ser explorado pela cultura do feijão?

5) Identificação de temas motrizes: os temas foram definidos com base em duas incertezas: o desenvolvimento tecnológico viabilizará o desenvolvimento da cultura? E, agregação de valor é o novo
- Cenário 1: Feijão com grande volume de produção;

- Cenário 2: Feijão com agregação de valor;

- Cenário 3: Feijão como produto de exportação.

Quadro 2: Matriz morfológicas dos cenários

\begin{tabular}{|c|c|c|c|}
\hline & $\begin{array}{l}\text { Cenário 1: Grande } \\
\text { volume de } \\
\text { produção }\end{array}$ & $\begin{array}{ll}\text { Cenário } & \text { 2: } \\
\text { Agregação } & \text { de } \\
\text { valor } & \end{array}$ & $\begin{array}{l}\text { Cenário 3: Produto } \\
\text { de exportação }\end{array}$ \\
\hline $\begin{array}{lr}\text { Desenvolvimento } & \mathrm{de} \\
\text { cultivares } & \text { mais } \\
\text { produtivas } & \end{array}$ & $\begin{array}{l}\text { Pequeno aumento } \\
\text { de cultivares mais } \\
\text { produtivos }\end{array}$ & $\begin{array}{l}\text { Sem evolução na } \\
\text { agregação de valor }\end{array}$ & $\begin{array}{l}\text { Poucos mercados } \\
\text { explorados }\end{array}$ \\
\hline $\begin{array}{l}\text { Desenvolvimento de } \\
\text { cultivares com maior } \\
\text { resistência a doenças }\end{array}$ & \begin{tabular}{|l} 
Cultivares \\
resistentes \\
doenças \\
mercado
\end{tabular} & Sem relação & $\begin{array}{l}\text { Possível aumento } \\
\text { de volume de } \\
\text { produção para } \\
\text { exportação }\end{array}$ \\
\hline $\begin{array}{l}\text { Aumento do consumo } \\
\text { de feijão }\end{array}$ & $\begin{array}{l}\text { Mantido o volume } \\
\text { de produção }\end{array}$ & $\begin{array}{l}\text { Pouco aumento } \\
\text { em produtos com } \\
\text { valor agregado }\end{array}$ & $\begin{array}{l}\text { Poucos mercados } \\
\text { explorados }\end{array}$ \\
\hline $\begin{array}{l}\text { Aceitação por parte dos } \\
\text { consumidores de } \\
\text { produtos com valor } \\
\text { agregado }\end{array}$ & \begin{tabular}{|lr} 
Possível & aumento \\
de produção & com \\
excedente & para \\
exploração & de \\
valor &
\end{tabular} & $\begin{array}{l}\text { Pouca aceitação } \\
\text { dos consumidores } \\
\text { a produtos com } \\
\text { valor agregado }\end{array}$ & $\begin{array}{l}\text { Possível } \\
\text { exploração de } \\
\text { mercados } \\
\text { estrangeiros com } \\
\text { produtos de valor } \\
\text { agregado }\end{array}$ \\
\hline $\begin{array}{l}\text { Aumento das } \\
\text { exportações do produto }\end{array}$ & $\begin{array}{lr}\text { Pouco volume } \\
\text { excedente para } \\
\text { exportação }\end{array}$ & $\begin{array}{l}\text { Pouca participação } \\
\text { no mercado } \\
\text { internacional }\end{array}$ & $\begin{array}{l}\text { Mercado abertos } \\
\text { para esse tipo de } \\
\text { produto }\end{array}$ \\
\hline
\end{tabular}

Fonte: elaborado pelo autor. 


\subsubsection{Discussão dos cenários}

Cenário 1: Feijão com grande volume de produção

Este cenário considera que haverá o aumento da produção de feijão com o desenvolvimento de novas tecnologias envolvidos no processo produtivo, como cultivares mais produtivas e melhores técnicas de cultivo. Esse cenário levou em consideração as novas cultivares que têm sido desenvolvidas para aumento da produção, nesse contexto, tem havido o desenvolvimento, mas longe do suficiente, de cultivares mais resistente tem conseguido mais êxito em seu desenvolvimento. $\mathrm{O}$ pouco volume produzido, não permite que a agroindústria agregue valor aos produtos. A demanda por feijão deve continuar aumentando, o volume deve evoluir junto, mas não acompanhando no sentido da produtividade por área e si no aumento das áreas produtivas.

Cenário 2: Feijão com agregação de valor

O grande incentivador para esse cenário é os mercados com maior exigência de produtos diferenciados. Mas esses mercados ainda são pequenos e o grande mercado, não aceita bem os produtos de feijão com valor agregado (feijão enlatado, feijão em basta, feijão pré-cozido, feijão verde, feijão germinado etc), com isso esse cenário tende a ter pouca exploração e a ter pouca evolução em relação ao mercado interno.

O mercado internacional apresenta maior recepção a produtos de feijão com valor agregado, mas o Brasil apresenta pouca participação nesses mercados, não havendo grande exploração deles.

Cenário 3: Feijão como produto de exportação

Esse cenário apresenta grande dependência do primeiro cenário. O Brasil vem apresentando aumento na sua produção de feijão, mas não é o suficiente para que haja exploração do mercado internacional, pois o volume produzido é quase todo consumido dentro do país, como observado por Assunção e Wander (2012), pouco volume é exportado, apenas para que Brasil participe do mercado. Os autores ainda destacam, que é importante ter participação, pois pode incentivar o aumento da produção, perfazendo um ciclo de aumento na produção, necessidade de mais produto para exportação, incentivando com preço a maior produção interna de feijão.

\subsection{Modelo teórico e metodologia para análise SWOT}

Após o levantamento da bibliografia, com decisão do trabalho no sentindo de analisar o desenvolvimento tecnológico e a produção para a cultura do feijão, a sistematização dos dados por meio da 
análise SWOT se ateve ao entendimento do macroambiente das tecnologias e o microambiente, referente à produção.

\subsubsection{Tecnologias e produção}

Silva (2002) define tecnologia como um conjunto de conhecimentos, princípios científicos, estudos e evoluções, que são aplicados a uma determinada atividade ou ramo do conhecimento para que haja a evolução e maximização dessa atividade.

Ferreira et al. (2002) destacam que as tecnologias para agricultura são o desenvolvimento de insumos que possam possibilitar o desenvolvimento e exploração da cultura em questão. Batalha e Silva (2007) definem insumos como produtos essenciais para a produção agrícola, sendo descritos, pelos autores, de forma simplificada como sendo todo material destinado à produção, compreendendo sementes, implementos, adubação, agroquímicos agrícolas, terra, entre outros.

Para Araújo (2007) a produção está envolvida com as atividades que ocorrem dentro da propriedade, sendo chamadas pelo autor de atividades "dentro da porteira". Batalha e Silva (2007) define o ambiente “dentro da porteira", é a transformação de diversos insumos no produto agropecuário.

\subsubsection{Pontos Fortes}

Depois da instalação do centro de pesquisa para a cultura de feijão, Embrapa Arroz e Feijão, na década de 70, verificou-se o constante desenvolvimento de novas pesquisas relacionadas com a criação de novas cultivares de feijão que fossem mais produtivas e com o porte mais ereto, para que facilitasse a colheita mecanizada da cultura. Cultivares com maior resistência a deficiência hídrica, resistentes a doenças e com maior produtividade.

Através de parcerias e convênios com outras unidades da Embrapa e com Universidades, foi possível o desenvolvimento de cultivares que conseguem se adaptar a todos os climas brasileiros. Atualmente, existem variedades disponíveis para cada região brasileira, onde elas conseguem expressar todo o seu potencial de produção, mesmo com o clima adverso.

$$
\text { O aumento do consumo do }
$$
produto dentro do território nacional tem se mostrado como um incentivo para o aumento da produção. O mercado interno sempre representou um mercado seguro para os produtores brasileiros no momento da comercialização de sua produção, pois o feijão faz parte dos produtos que estão na pauta do consumo diário do brasileiro. 


\subsubsection{Pontos fracos}

O novo cenário de desenvolvimento da agricultura não tem beneficiado a cultura do feijão, culturas com melhores preços, soja, cana-de-açúcar, milho e tomate, tem invadido as áreas de produção de feijão, forçando a produção dessa cultura a ficar quase que restritas as propriedades que acompanham os moldes da agricultura familiar. $\mathrm{O}$ avanço, principalmente, da cultura da cana-de-açúcar tem diminui a disponibilidade de terras para a cultura do feijão.

Como o feijão faz parte da dieta básica do brasileiro, o governo impõe pressões de preços para que o valor na comercialização com o consumidor não seja alto, com isso o feijão segue tendo preços de comercialização baixos e oscilantes, em alguns períodos os preços estão alto e em outros os preços estão baixos, fazendo com que a cultura enfrente uma gangorra comercial em relação ao seu mercado.

Insumos, defensivos agrícolas, com alto valor no mercado e os investimentos iniciais em sistemas de irrigação, causam o desincentivo na migração de produtores de outras culturas para a cultura do feijão.

\subsubsection{Oportunidades}

Mercados crescentes de consumo de feijão no mundo. Com crescimento acentuado de população em países emergentes, o mercado de feijão brasileiro pode encontrar oportunidades de exploração desses mercados com seu produto, podendo ser competitivo na agregação de valor a matéria-prima a comercialização com esses países.

Cultivares lançadas pela Embrapa que apresentam maior produtividade em relação às antigas cultivares, podendo com isso, mesmo havendo a diminuição de áreas produtivas, manter ou aumentar, como tem sido o cenário, a produção de feijão nas áreas agricultáveis.

O crescente consumo de feijão no mercado interno. $\mathrm{O}$ Brasil pode fazer investimentos e render a pressão de preços, para que mais produtores possam iniciar a produção de feijão, visando o suprimento do mercado interno e diminuído o volume de feijão importado pelo Brasil.

\subsubsection{Ameaças}

Variação nos preços de comercialização da produção, apresentando muitas oscilações no decorrer do ano. Uma variação durante o ciclo produtivo da cultura pode representar ganho ou perda significativa para o produtor rural, sendo esse uma forte ameaça a permanência dos produtos no cultivo dessa cultura.

Devido à diminuição no tempo de produção ocorrido nos últimos anos, a exigência de grandes investimentos em mecanização da produção, tem diminuído a 
participação de produtores que não conseguem ter acesso a essas tecnologias. O principal problema é no momento da colheita, poucas cultivares apresentam o porte ereto, que possibilita a colheita mecanizada da produção.

Cultura pouca mecanizável, com os produtores encontram dificuldades em encontrar mão de obra disponível para a Quadro 3: Análise SWOT da cadeira produtiva do feijão

\begin{tabular}{|c|c|c|c|}
\hline \multicolumn{2}{|c|}{ Análise Interna } & \multicolumn{2}{|c|}{ Análise Externa } \\
\hline Pontos Fortes & Pontos Fracos & Oportunidades & Ameaças \\
\hline $\begin{array}{l}\text { Desenvolvimento } \\
\text { de cultivares com } \\
\text { porte mais eretas e } \\
\text { mais produtivas }\end{array}$ & $\begin{array}{l}\text { Crescimento de } \\
\text { culturas sobre as } \\
\text { áreas de produção } \\
\text { de feijão }\end{array}$ & $\begin{array}{l}\text { Mercado } \\
\text { internacional } \\
\text { crescente no } \\
\text { consumo de feijão }\end{array}$ & $\begin{array}{l}\text { Grandes oscilações } \\
\text { nos preços de } \\
\text { comercialização } \\
\text { durante o ciclo } \\
\text { produtivo }\end{array}$ \\
\hline $\begin{array}{ll}\text { Cultivares } & \\
\text { adaptadas } & \text { a } \\
\text { diferentes } & \text { climas } \\
\text { brasileiros } & \end{array}$ & $\begin{array}{ll}\text { Preço } & \text { de } \\
\text { comercialização } & \\
\text { oscilante } & \text { no } \\
\text { mercado } & \end{array}$ & $\begin{array}{l}\text { Lançamento de } \\
\text { cultivares mais } \\
\text { produtivas e de } \\
\text { possível exploração } \\
\text { da mecanização }\end{array}$ & $\begin{array}{ll}\text { Alto custo } & \text { da } \\
\text { mecanização } & \text { da } \\
\text { produção } & \end{array}$ \\
\hline $\begin{array}{l}\text { Alto consumo } \\
\text { interno de feijão }\end{array}$ & $\begin{array}{l}\text { Investimento } \\
\text { iniciais muito alto }\end{array}$ & $\begin{array}{l}\text { Crescente consumo } \\
\text { interno de feijão }\end{array}$ & $\begin{array}{l}\text { Pouca mão de obra } \\
\text { no momento da } \\
\text { colheita } \\
\text { produção }\end{array}$ \\
\hline
\end{tabular}

Fonte: Elaborado pelo autor.

\section{CONSIDERAÇÕES FINAIS}

O desenvolvimento de tecnologias específicas para a cultura do feijão tem demonstrado que a cultura tem apresentado grande potencial de crescimento em sua produção. Esse desenvolvimento pode colheita da cultura, com isso o feijão chega a seu período de colheita sem haver mão de obra suficiente, causando perdas para os produtores de feijão ainda no campo. 
consumo do feijão em estado natural ou com valor agregado para consumo.

$$
\text { Cada cenário traz possíveis }
$$
consequências para o setor e, mesmo que um deles apresente maior propensão a acontecer, é relevante que todos os cenários, dado que são cenários plausíveis de acontecimento, estejam em discussões em torno das ações que podem ser tomadas para o desenvolvimento da cadeia produtiva do feijão. $\mathrm{O}$ feijão participa da dieta básica do brasileiro, apresentando grande assim importância substância no cenário produtivo nacional, o Brasil deve observar quais são as linhas que seguem para que entrem em consonância com a estratégia adotada atualmente.

Com relação ao mercado interno do setor feijoeiro, há grandes chances de crescimento para a cultura, desde que haja maior investimento por parte dos governos em equilibrar os preços pagos aos produtores, fazendo com que cadeia não apresente mais o

\section{REFERÊNCIAS}

\section{ALMEIDA, M. I. R. Manual de}

planejamento estratégico: desenvolvimento de um plano estratégico com a utilização de planilhas Excel. 3 ed. - São Paulo: Atlas, 2010.

\section{ARAÚJO, M. J. Fundamentos de}

agronegócio. 2 ed. - São Paulo: Atlas, 2007. efeito gangorra, com grandes oscilações de valor pago aos produtores. O mercado externo apresenta potencial de exploração, desde que o Brasil consiga suprir sua demanda interna, possível apenas com o aumento da produtividade, deixando de importar tanto feijão e conseguido reter excedentes para a exportação.

A definição de competitividade tem base na capacidade de sobrevivência e crescimento que a atividade apresenta em relação aos concorrentes e aos novos mercados, e isso tem relação direta com as ações tomadas pelos coordenadores das organizações. $\mathrm{O}$ feijão apresenta baixa competitividade em relação a suas culturas concorrentes, mas apresenta cenários de ações favoráveis para que haja ao aumento da competitividade. É necessário a tomada de ações conjuntas entre os elos para que se consiga trabalhar os pontos fracos $\mathrm{e}$ as ameaças que cultura enfrenta.

ASSUNÇÃO, P. E. V.; WANDER, A. E.

Orientação regional das exportações

brasileiras de feijões, 2002 a 2010 . In. 50

CONGRESSO DA SOCIEDADE

BRASILEIRA DE ECONOMIA E

SOCIOLOGIA RURAL, 2012, Vitória.

Anais... Brasília: SOBER, 2012, meio

eletrônico. Disponível em:

$<$ http://icongresso.itarget.com.br/useradm/ana

is/?clt=ser.2>. Acesso em: 02 de julho 2012. 
BARBOSA, F. R.; GONZAGA, A. C. O.

Informações técnicas para o cultivo do feijoeiro-comum na Região Central-

Brasileira: 2012-2014. Santo Antônio de

Goiás: Embrapa Arroz e Feijão, p. 247, 2012.

Série Documentos.

BARBOSA, A. P. P. L.; JÚNIOR GATTI, W.

Cenários tecnológicos para a demanda por cana-de-açúcar. Future Studies Research

Journal, São Paulo, v. 4, n. 1, p. 92-113, janjun. 2012.

BATALHA, M. O.; SILVA, A. L.

Gerenciamento de sistemas agroindustriais:

definições, especificidades e correntes

metodológicas. In. BATALHA, M. O.

(Coord.). Gestão agroindustrial. 3 ed. São

Paulo: Atlas, 2007, cap. 1, p. 1-62.

BRASIL. Projeções do Agronegócio

2010/2011 a 2020/2021. Brasília. 2011.

CALAES, G. D.; VILLAS BÔAS, R. C.; GONZALES, A. Planejamento estratégico, competitividade e sustentabilidade da indústria mineral: dois casos de não metálicos no Rio de Janeiro. 1 ed. Rio de Janeiro: Cyted, 2006.

CASTRO, A. M. G.; LIMA, SUZANA, M. V.; BORGES-ANDRADA, J. E.

Metodologia de planejamento estratégico das unidade do Ministério da Ciência e
Tecnologia. Brasília, DF: Ministério da

Ciência e Tecnologia, Centro de Gestão e

Estudos Estratégicos, 2005.

CHIAVENATO, I.; SAPIRO, A.

Planejamento estratégico: fundamentos e aplicações. Rio de Janeiro: Elsevier, 2003 - $5^{\text {a }}$ Reimpressão.

COATES, J. F. Scenario planning.

Technological Forecasting and Social

Change. Nova York, v. 65, n. 1, p. 115-123, set. 2000 .

\section{DAYCHOUW, M. 40 Ferramentas e} técnicas de gerenciamento. 3 ed. Rio de Janeiro: Brasport, 2007.

DYSON, R. G. Strategy development and SWOT analysis at the University of Warnick.

\section{European Journal of Operational}

Research, n. 152, p. 631-640.

EMBRAPA. EMPRESA BRASILEIRA DE PESQUISA AGROPECUÁRIA. Cadeia de Produção do Feijão. Disponível em:

$<$ http://www.cnpaf.embrapa.br> Acesso em: 18 de abr. 2012

FAHEY, L.; RANDALL, R. M. Learning from the future - competitive foresight scenarios. New York: Wiley, 1998.

FARINA, E. M. M. Q. Conceitos:

competitividade e coordenação de sistemas 
agroindustriais. In. FARINA, E. M. M. Q.;

ZYLBERSZTAJN, D. Competitividade no

agribusiness brasileiro: introdução e

conceitos. São Paulo: Pensa/FIA/FEA/USP,

1998, v.1, cap. 2, p. 10-32.

FARINA, E. M. M. Q.; ZYLBERSZTAJN,

D. Competitividade e organização das

cadeias agroindustriais. San José: Instituto

Interamericano de Cooperação para a

Agricultura, 1994. 63 p.

FERREIRA, C. M.; DEL PELOSO, M. J.;

FARIA, L. C. Feijão na econômica

nacional. Santo Antônio de Goiás: Embrapa

Arroz e Feijão, p. 48, 2002. Série

Documentos.

FERRAZ, J. C; KUPFER, D;

HAUGUENAUER, L. Made in Brazil:

desafios competitivos para a indústria. Rio

de Janeiro: Campus, 1996.

FUSCALDI, K. C.; MARCELINO, G. F.

Análise SWOT: o caso da secretária de

política agrícola. In. $46^{\circ}$ Congresso da

Sociedade Brasileira de Economia,

Administração e Sociologia Rural, 2008, Rio

Branco. Anais...Brasília: SOBER, 2008, meio

eletrônico. Disponível em:

$<$ http://www.sober.org.br/palestra/9/451.pdf>.

Acesso 18 de jan. 2013

GIL, A. C. Como elaborar projetos de

pesquisa. 4 ed. São Paulo: Atlas, 2009.
GODET, M. Manual de prospectiva

estratégica: da antecipação a ação. Lisboa:

Dom Quichote, 1993.

GODET, M. The art of scenarios and strategic planning: tools and pitfalls. Techonological

Forecastingand Social Change. Nova York, v. 65 , n. 1 , p. $3-22$, set. 2000.

HUSS, W. R. A move toward scenario

analysis. Internacional Journal of

Forecasting. Nova York, v. 4, n. 3, p. 377-

388, 1988.

JOÃO, I. S.; LOURENZANI, W. L. análise

SWOT do sistema agroindustrial do

amendoim na região de Tupã e Marília - SP.

Revista Organizações Rurais e

Agroindustriais. Lavras, v. 13, n.2, p. 243-

256, 2011.

MARTINS, L. Marketing: Como se tornar um profissional de sucesso. 1 ed. São Paulo:

Digerati Books, 2006.

MARTINS, M. A. P. Gestão educacional:

planejamento estratégico e marketing. 1 ed.

Rio de Janeiro: Brasport, 2007.

MATOS, J. G.; MATOS, R. M. B.;

ALMEIDA, J. R. Análise do ambiente

corporativo: do caos organizado ao

planejamento. 1 ed. Rio de Janeiro: E-

papers, 2007. 
MORAIS, M. A análise SWOT aplicada às

vendas de hoje. Disponível em:

$<$ http://www.artigonal.com/vendas-artigos/a-

analise-swot-aplicada-as-vendas-hoje-

352133.html>. Acesso em: 17 de jan. 2013.

MÜLLER, C. J. Modelo de gestão integrado

planejamento estratégico, sistemas de

avaliação de desempenho e gerenciamento

de processos (MEIO - Modelo de

estratégia, Indicadores e Operações). 2003.

Tese (Doutorado em Engenharia de Produção)

- Universidade Federal do Rio Grande do Sul,

Porto Alegre, 2003.

PEREIRA, F. F. P. et al. Prática da gestão do conhecimento em empresas públicas. 1 ed. Rio de Janeiro: E-papers, 2002.

POTER, M. A Nova estratégia. In. JÚLIO, C.; SALINI NETO, J. (Orgs.). Estratégia e Planejamento. 1. ed. São Paulo: Publifolha, 2002.

PORTER, A.; ROPER, A. T.; MASON, T.;

ROSSINI, F. A.; BANKS, J.;

WIEDERHOLT, B. J. Forecasting and management of technology. New York: John Wiley \& Sons.

RAELE, R. Aplicação de um modelo de construção de cenários no setor produtivo do etanol: um estudo de caso sobre o etanol de segunda geração. Dissertação de
Mestrado, Faculdade de Economia,

Administração e Contabilidade da

Universidade de São Paulo: São Paulo, SP,

Brasil, (2010).

REZENDE, D. A. Planejamento estratégico para organizações: públicas e privadas. 1 ed. Rio de Janeiro: Brasport, 2008.

ROUBELAT, F. Scenario planning as a networking process. Technological

Forecasting and Social Change. Nova York, v. 65 , n. 1, p. 99-112, set. 2000.

RODRIGUES, J. N. et al. 50 gurus para o século XXI. 1 ed. Lisboa: Centro Atlântico. PT, 2005.

SCHNAARS, S. P.; TOPOL, M. T. The use of multiple scenarios in sales forecasting.

Internacional Journal of Forecastingn, v. 3, n. 3-4, p.405-419, 1987.

SCHOEMAKER, P. J. H. Scenario planning: a tool for strategic thinking. Sloan

Management Review, Boston, v.36, n.2, p.25-40, Winter, 1995.

SCHWARTZ, P. A arte da visão de longo prazo. São Paulo: Nova Cultural, 2000.

SELLTIZ, C; WRIGHTSMAN, L. S.; COOK, S. W. Métodos de pesquisa nas relações sociais. São Paulo: Epu, 2004. 
SIFFRET FILHO, N.; FAVERET FILHO, P.

O sistema agroindustrial de carnes:

competitividade e estruturas de governança.

Revista BNDES, Rio de Janeiro, n. 10, dz, 1998.

SILVA, J. C. T. Tecnologia: conceitos e dimensões. In. XXII Encontro de Engenharia de Produção. Curitiba. Anais... São Paulo, ABREPO, 2002, meio eletrônico. Disponível em: $<$ http://www.abepro.org.br/biblioteca/ENEGEP 2002_TR80_0357.pdf>. Acesso em 22 de jan. 2013.

SILVA, A. T. B.; SPERS, R. G.; WRIGHT, J. T. C. A elaboração de cenários na gestão estratégica das organizações: um estudo bibliográfico. Revista de Ciências da Administração, v. 14, n. 32, p.21-34, abr. 2012.

SILVA, A. A.; SILVA, N. S.; BARBOSA, V. A.; HENRIQUE, M. R.; BARTISTA, J. A. A utilização da matriz Swot como ferramenta estratégica - um estudo de caso em uma -abr, 2006. escola de idioma de São Paulo. In. VIII Simpósio de Excelência em Gestão e Tecnologia. Resende. Anais...Santa Catarina, SEGeT, 2011, meio eletrônico. Disponível em:

$<$ http://www.aedb.br/seget/artigos11/2671425

5.pdf>. Acesso em: 19 de jan. 2013.

SOUZA, I. D. S.; TAKAHASHI, V. P. A visão de futuro por meio de cenários prospectivos: uma ferramenta para a antecipação da inovação disruptiva. Future Studies Research Journal. São Paulo, v. 4, n. 2, p. 102-132, jul-dez. 2012.

WRIGHT, J.; SPERS, R. O país no futuro: aspectos metodológicos e cenários. Estudos Avançados, São Paulo, v.20, n.56, p.13-28, jan 